\title{
Amor cortés y amor mercantil: conceptos amatorios enfrentados
}

\author{
Simon Kroll \\ Universidad de Viena
}

\section{RESUMEN}

En el artículo se trata de situar la Segunda Celestina de Feliciano de Silva en su contexto histórico, especialmente en el pensamiento económico de su época. Se analiza que el texto presenta diferentes modelos amatorios. La mayoría de las relaciones corresponderían a un amor mercantil que reifica al otro. Frente a este amor economizado se dibuja una pareja de amor noble y cortés y un discurso de amor pastoril que pueden verse como contrastes de las relaciones mercantilizadas. Se argumenta, por ende, que el texto de Silva, lejos de propagar una vuelta a valores medievales, discute diferentes modelos amatorios e inserta su texto en el contexto de la creciente mercantilización del temprano siglo XVI.

PALABRAS CLAVE: mercantilización, reificación, amor mercantil, economía, Segunda Celestina.

\section{Courtly love and commercial love: opposing love concepts}

\section{ABSTRACT}

This article situates the Segunda Celestina by Feliciano de Silva in his historic context, especially in the context of the economic thinking of its time. The authors analyzes that the text offers different love models. The majority of the relationships in the text corresponds to an economized love which objectifies the other. In contrast to this economized love their appears an example of courtly love and one of pastoral love. The text concludes, then, that Silva's text is far from proclaiming medieval values, but participates in the XVI-century discussions of an increasing mercantilisation.

KEY WORDS: mercantilisation, reification, economic love, economics, Segunda Celestina. 


\section{Contextos}

Es un lugar común situar los comienzos de la globalización y del primer capitalismo a finales del siglo XV y comienzos del siglo XVI. Esta época conoció un aumento extraordinario en la mercantilización de las relaciones humanas, así como los principios del establecimiento de un sistema de valor global. Las constantes referencias al oro en las crónicas, diarios y relaciones del 'Nuevo Mundo' son, desde el Diario de a bordo, de Colón, archiconocidas; así como el tópico de la supuesta codicia de los navegantes y traficantes que se mueven entre América y Europa. Todas las acciones de los navegantes y conquistadores españoles pivota sobre el ansia por el oro, de manera que personas como Bartolomé de las Casas elevaron rápidamente el grito al cielo para denunciarlo.

La creciente llegada de riquezas a España desde las Américas, así como el creciente volumen de créditos debido a los viajes y comercios transatlánticos, causaron una subida enorme de los precios en la península ibérica, cambiando profundamente la España de la época (Grice-Hutchinson 1952: 2-4). Grice-Hutchinson lo describe así:

For a little time fortunes could still be made in the New World by the old traditional method of conquest, the acquirement of land and booty, and the virtual enslavement of the conquered peoples. But in Spain itself things had changed. Accounting skills, quickness of intellect, and knowledge of commercial practice were now the keys to prosperity. And of such a training the hidalgo had but little, contenting himself with consolidating the territorial gains he had achieved in the Reconquest. (1992: 184)

El mercantilismo creará un grupo importante de obreros asalariados que trabajan en las viñas, las salinas, la plantación de moras y la producción de seda, entre otras cosas. La producción de cash-crops se generaliza ${ }^{1}$. Navarro Gala apunta, analizando el sistema de cortesía en la Segunda Celestina:

El ascenso de una nueva "clase» dominante cuyo poder se expresa a través de la ostentación, transforma el sistema de valores, provocando la crisis de la sociedad. De este modo se quiebra el antiguo orden social que estaba basado en una moral de valores y virtudes objetivos e inmutables, y empieza a configurarse un nuevo orden cuyo cimiento es el dinero. (2004: 215) 
Las novedades y los problemas (inflación, impuestos altos) que se están produciendo en el mercado fuerzan hasta a los intelectuales más destacados de la época a formular respuestas o consejos. ¿Cómo determinar un precio justo?; ¿bajo qué condiciones son admisibles los intereses provenientes de préstamos? (También entonces sabían que ni la reconquista, ni el descubrimiento y la colonización de América habrían sido posibles sin poder pedir créditos y préstamos). Teólogos de Salamanca, como Francisco de Vitoria, Martín de Azpilcueta o Tomás de Mercado trataron de formular respuestas a estos problemas con la intención de darles un fundamento moral y teológico y asentaron las bases de lo que hoy en día llamamos economía. Elaboraron nuevas teorías del valor y de la moneda basándose en la escolástica medieval, vieron la influencia de la llegada de las riquezas americanas en la economía española y crearon teorías del intercambio de monedas de diferentes estados ${ }^{2}$. Su teoría del valor pone especial énfasis en la evaluación subjetiva de un bien:

I teologi spagnoli formularono una teoria soggettiva del valore, secondo la quale il valore di un bene non era determinato dai fattori dei costi di produzione e dal lavoro necessario per produrlo, ma dalla valutazione soggettiva e dalla stima degli individui nei casi concreti della realtà economica. (Franco 2015: 43)

Los cambios económicos profundos que llegaron a crear la escuela de Salamanca (1534 en adelante), como la conocemos hoy en día, son el trasfondo cultural del autor al que se dedica este artículo: Feliciano de Silva.

Este escritor conoció el fenómeno del comercio transatlántico, estuvo en Sevilla y América; su hijo Diego de Guzmán de Silva luchó en el Perú y es tenido por el primer poeta de lengua española en el continente americano. Su padre, Feliciano, es sobre todo conocido por sus continuaciones literarias; entre otras cosas, escribió hacia 1534 una Segunda Celestina, que constituye la primera continuación de la obra rojana y que da lugar al ciclo celestinesco ${ }^{3}$. De su vida sabemos poco además; está documentado que tras un pleito con su propio tío, en el que este le acusaba de comunero a favor de la Junta de Tordesillas, le fue otorgado un puesto vitalicio de regidor (Baranda 1988: 31). Por ende, podemos inferir que el propio Feliciano de Silva estuvo en posiciones importantes para observar y entender la influencia de una mercantilización generalizada en la vida de las personas.

2.- Ver Grice-Hutchinson (1992).

3.- Luis Mariano Esteban (1991-1992) analiza la función de la Segunda Celestina en el ciclo celestinesco. 


\section{Análisis de los discursos de amor en la Segunda Celestina}

La Segunda Celestina de Feliciano de Silva es un texto con elementos paródicos y satíricos, exageraciones y ridiculizaciones, que elabora una comicidad basada principalmente en la deformitas: una Celestina cuyas mentiras son reveladas instantáneamente, un criado de espuelas que se muere de miedo a pesar de sus soliloquios grandilocuentes, referencias a refranes populares, comida, bebida y sexo son los pilares de la comicidad de la que se nutre el texto; juega con una ironía dramática casi constante, la mayor consiste en lo que concierne a la supuesta santidad de Celestina. Después de su muerte al final de la Tragicomedia de Calisto y Melibea estuvo en una especie de inframundo del que "supo» volver. Es decir: Celestina resucitó, término cristiano que ella usa también a lo largo del texto. Su resurrección es desde el principio reconocible como una embustería. Sin embargo, ella trata de construir una imagen de sí misma como santa, según sus propias palabras. La Celestina de Feliciano de Silva es naturalmente también alcahueta y madre de prostitutas, pero el texto crea comicidad a partir de la discrepancia entre sus intentos de aparentar santa y sus fechorías. Buen ejemplo de ello da una escena en la que Elicia, una de las jóvenes bajo la cautela de Celestina, tiene una visita masculina, Crito, y Celestina dice:

Celestina. ¿Fuese ya Crito?

Elicia. ¿Cuándo diablos se havía de ir?, antes está en el sobrado escondido.

Celestina. Pues no le hables de aquí adelante sino fingiendo que yo no lo sé ni me passa por pensamiento, y no digo más a él que a otro; porque ya sabes que si por camino de santidad no vamos, que somos ya tomados con el hurto; y desvíate allá y haré como que no sé que está acá. ¿Quién era aquel galán, Elicia, que te hablava denantes en el portal?

ELICIA. ¿No lo conociste que era Crito?

Celestina. ¿Qué Crito, ni que Crita? No me entre hombre en esta casa, que no vengo acá al siglo para tornar a pagar pecados agenos. (306) ${ }^{4}$

La Celestina de Feliciano de Silva es probablemente menos diabólica que la de Rojas: tiene poco conocimiento mágico, no pronuncia conjuros, sino que solo acuerda citas entre amantes que ya se quieren, como ya 
había notado la crítica (Menéndez Pelayo 1943: 72)5. Es una casamentera. Especialmente por la presencia de las cartas que se escriben los enamorados la alcahueta es "un elemento más, y no exclusivo, para la consecución de los favores de la dama» (Mariano Esteban 1991-1992: 43). Su intervención es además bastante tardía y su actuación en la trama principal no es el plano más importante de la elaboración del personaje. "En realidad, cuando Celestina visita a Polandria para convencerla de que acepte el trato de Felides (jen la escena XX!), ella ya se ha confesado enamorada, y dama y doncella se sirven de la tercera para alcanzar su propósito: organizar un encuentro con el protagonista", escribe Sánchez Bellido al respecto (2010: 755). Esta reducción de los personajes a medios para conseguir un bien participa de la reificación del hombre, se vuelven instrumentos que en la mayoría de los casos sirven para conseguir algún lucro (Pandulfo y Palana, por ejemplo).

Francisco Rodríguez Cascante compara las Celestinas de Rojas y de Silva y argumenta que la segunda sería mucho más conservadora, medieval y en su configuración como personaje unidimensional. Efectivamente puede decirse que la influencia de la Celestina de Silva sobre la trama amorosa principal es bastante reducida, pues no interviene en el enamoramiento y tan solo sirve para acordar citas. La pujanza principal de la dama protagonista hacia el casamiento con Felides resulta de la criada Poncia. De manera que Rodríguez Cascante opina que «Polandria [...] no piensa por sí misma» y que «de Silva propone una Celestina desdibujada que es derrotada por una criada inmersa en los valores medievales, que defiende el honor y el matrimonio como los fines últimos de la existencia» (2001: 38). Rodríguez Cascante resume su comparación de los dos textos celestinescos de la siguiente manera:

La Segunda Celestina procura resolver esa ambigüedad y retomar los cánones institucionales medievales como garantes de la verdad y la seguridad. Es por ello que en esta obra Segunda Celestina no se presenta ni el suicidio ni la muerte como opciones de los actantes, sino el matrimonio de los amantes y la defensa del honor de los personajes. De Silva obvia el elemento trágico y resuelve el conflicto planteado por Rojas instaurando un «final feliz». Es así como regresa al paradigma medieval y no lee la propuesta que subyace en la ambigüedad de Celestina: cada personaje tiene un destino individual que debe resolver al margen de los códigos fijados por las instituciones juzgadas decadentes. (39) 
Las conclusiones de Rodríguez Cascante tienen varios problemas: la dificultad de analizar el pensamiento implícito de un personaje y su concentración exagerada en la trama amorosa principal. Su juicio bastante demoledor podría matizarse teniendo en cuenta las demás tramas del texto, así como la constante ironía dramática que deja bien claro que la Celestina no se ha convertido en una religiosa, como Cascante también concluye (2001: 36).

Cierto es que los aspectos de la hechicería y brujería, los conjuros y pactos diabólicos, el conocimiento del poder de las especias y pócimas, están mucho menos presentes en el texto de Silva. Así, cuando la Celestina de Silva trata de aparentar tener más conocimientos que el resto de los mortales «normales», la ironía dramática convierte la situación inmediatamente en risible, lo cual ya pone en entredicho el análisis de Cascante de la supuesta religiosidad de la Celestina de Silva. Ésta es un personaje principalmente picaresco, cuyo único interés es el dinero, el vino y la comida, de manera que la supuesta vuelta al mundo de los valores medievales solo cuenta con una presencia muy parcial en el texto.

En definitiva, el texto despliega varios modelos del discurso amatorio distintos que se cristalizan específicamente en las diferentes configuraciones del personaje celestinesco. La Segunda Celestina parece haberse escrito bajo una marcada influencia del creciente mercantilismo a comienzos del siglo xvi. Esto se evidencia especialmente en el tratamiento del amor. Como ya vimos, la trama de la Segunda Celestina conoce una pareja protagonista, Felides y Polandria. Aparte de ellos dos, hay una serie de tramas secundarias entre damas y caballeros que oscilan entre relaciones de amor y de prostitución. Es llamativo que todas estas relaciones estén principalmente regidas por intereses económicos. La Celestina de Silva lo deja bien claro; cuando Elicia está indecisa entre los amores del ya mencionado Crito y del señor Barrada, el primero pobre y el segundo rico: «Elicia. Quiero dezir que mejor es tener al paje del infante para mi honra, con el mediano interesse de Crito, que no todo el interesse de Barrada con la falta de su linaje» (531). Primero es de notar cómo Elicia usa el término «interesse» para referirse a los bienes financieros de sus dos pretendientes. Pues se trata de un término del derecho romano, adaptado al sistema de créditos medieval por Raymond de Peñafort, que es, debido a los problemas de la licitud del crédito en el siglo xvI, axial para los debates económicos de la época (Grice-Hutchinson 1992: 180-182). La respuesta de Celestina a las dudas de Elicia se nutre de un mercantilismo desenfrenado:

Celestina. ¡Qué negro linage, y qué negra nada de honra! Como si no supiesses, hija, que todos somos hijos de Adán y Eva. Y por aquí verás, mi amor, que sola la riqueza haze el linaje; porque créeme, hija, que como ya todo lo que se compra y se vende anda puesto a peso y medida, assí anda la honra y el linaje a peso y medida, 
de ser más y valer más no el que más vale de persona, mas el que más vale su hazienda, no el que tiene de virtud y linaje, mas el que más tiene de falta de todo esto con sobra de lo contrario para saber adquerir más dinero. (531-532)

En esta concepción de las relaciones humanas todo depende del dinero, del valor mercantil que uno haya reunido. La hacienda de una persona se convierte en el único criterio para apreciarlo, ni títulos nobles están exentos de esto: "porque a un conde se haze con más de hazienda la honra, que a un duque no se haze con menos de tal interés» (532); ni títulos eclesiásticos: "mira la diferencia de la honra que se haze a un obispo de anillo, a la de otro obispo de mayor renta con igual dinidad y ditado» (532). La joven Elicia tiene sus dudas: "Por cierto, tía, pues yo he oído dezir que dizen los sabios que más vale saber que haver, virtud que riqueza» (533). No obstante, Celestina sigue elaborando su discurso organizado únicamente por una idea mercantil: "Eso, hija sería en otro tiempo, mas no en éste, que ya sabes que dize el proverbio que cada cosa en su tiempo. [...] y por aquí verás que el tiempo quiere lo que se usa en él, engendrado por él, qu'es el dinero" (533). La vieja alcahueta expresa una clara consciencia de que la supremacía del dinero es un fenómeno de su tiempo y parece apuntar además, al tema del préstamo y los intereses, puesto que el tiempo engendra dinero en el proceso de dar un crédito.

Desde la primera aparición de la vieja codiciosa se evidencia esta supeditación de las relaciones al dinero. Recién vuelta a casa, pregunta a Elicia que se ha hecho del dinero y de la cadena que había recibido de premio en la Tragicomedia. Esta trata de engañarla pero la Celestina es suficientemente astuta e insiste:

Celestina. Por mi vida, que digas; a ver si me dixo Plutón la verdad, o si es lo que yo sé.

Elicia. Pardiós madre, doze monedas tengo gastadas y la cadena entera está, como tú la dexaste escondida.

Celestina. Por tu vida, tanto me dixo Plutón que havías gastado.

ELICIA. Pues por mi vida, que mintió; que no tengo gastadas más de ocho.

Celestina. Por tu vida, que esso es lo que yo sabía, y el traidor siempre acostumbró mentir. (199)

Como señala Heugas: "On voit que ce tait initial de La Célestine permet ici une amplification comique et comment le texte modèle a nourri l'imitation" (1973: 56). La obra pone, pues, de manifiesto la mercantilización de las relaciones humanas, así como ridiculiza las consecuencias 
de este mismo proceso. "Amores, y diablos y dineros no se pueden encubrir», que es uno de los refranes más citados, funciona, por tanto, casi como lema para toda la obra.

Hay muchas relaciones principalmente organizadas por el dinero en este texto, la relación entre Pandulfo y Palana supone otro ejemplo, puesto que Palana es en un principio la amante de Pandulfo así como la prostituta que explota. Se trata de los amores mercenarios, como los había denominado Consolación Baranda (1988: 71-72). Su «finalidad inmediata es el lucro» (1988: 72) y de esta forma puede constatarse una cosificación muy extendida de las relaciones humanas entre los diferentes personajes. Cada uno ve al otro solo como un medio para alcanzar un determinado propósito que en la mayoría de los casos es uno mercantil: ganar dinero.

Ya se había adelantado que el discurso mercantilista del texto conoce excepciones que es la pareja de Polandria y Felides y el amor del pastor Filíndes. El amor cortés y el amor noble operan, pues, como una especie de contraejemplo para los amores mercenarios. La criada Poncia tiene al respecto una posición ambigua, casi de bisagra. Por un lado, aconseja a Polandria pensar en su honra y linaje cuando comienza a relacionarse con Felides. Le dice:

Y para que este he pensado que sería bien, si alguna cosa de su parte te dixessen, pedille que se case contigo secretamente, porque público pienso que tu madre no querrá, porque aunque él es tan rico y de muy buen linaje, ya sabes que tu mayorazgo que no puedes heredallo casándote fuera de tu linaje. (389)

Menciona la riqueza como un detalle importante, pero opina que "por mejor tendría la pérdida de la hazienda que la de la honra», pero solo porque «su riqueza suplirá la falta de la tuya» (389-390). A pesar de su mención de la honra que, según Francisco Rodríguez Cascante, es un indicio de la vuelta a valores medievales en el texto de Silva, es evidente que Poncia conceptualiza relaciones humanas también a partir de su valor monetario. Así, cuando su relación con Sigeril, criado de Felides, se iba a concretizar, ella tiene un gran inconveniente: la falta de dineros de su pretendiente:

Poncia. Mas ipara qué quieres que te lleve? porque aunque tengas amores y diablos, si no tienes dineros, maldita la necessidá que de ti tengo.

Sigeril. ¿Y qué sabes, tú señora, si los tengo?

PonCIA. ¿Tú no dizes que no se pueden encobrir? Pues ya te prometo, que si los tienes, que el proverbio mienta, porque los tienes tan secreto, que podemos dezir por ti que aun el mismo moro no lo sabe. (454) 
Bastante desconcertado responde Sigeril después de un rato: «Señora mía, no pensé yo que en precio pusieras lo que yo juzgava sin ninguno» (454). Para Poncia importa la honra y el dinero: «Pues agora sabes tú que sin él no se han las mugeres. Pues sabe, si no lo sabes, que con limpieza y dineros me has de alcançar, que no por diablos y amores» (454). Y aunque se trate de un tópico muy extendido en el discurso amoroso es llamativo cómo argumenta con las palabras «pagar» $\mathrm{y}$ «deber»:

Y para pagarte el amor que me tienes, te pago amostrándote el amor que me deves tener, y no el que ni me deves ni te deves, y por él te devo menos, cuanto te devríamás con amarme de limpio y verdadero amor virtuoso, y no para conformidad de vicios. Y no llames ni pongas nombre de amor al amor que con tanto desamor procura deshazer lo que más se precia y poner desprecio en la que ama, que es la castidad y limpieza de las mugeres. (456)

Lo que parece una reinstalación de un discurso de honra, que, por otra parte, tampoco es tan medieval, en realidad eleva al dinero como la segunda fuente principal para la licitud o ilicitud de un amor. El limpio y verdadero amor es el que no busca una satisfacción rápida de vicisitudes, sino el que significa una real propuesta de matrimonio, la cual tiene que estar fundamentada en una buena cantidad de dinero. La base de este amor limpio por parte del hombre es el dinero; el amor que no está basado en este, desprecia lo que más se precia en las mujeres: su castidad. Poncia es un personaje a caballo entre un sistema mercantilista y uno basado en el vasallaje y el intercambio de servicios ${ }^{6}$.

La concepción del amor casi exclusivamente mercantil se confronta con el amor entre Polandria y Felides, ejemplo del amor cortés. Entre ellos dos hay un amor de índole noble con rasgos neoplatónicos. Importante es al respecto el proceso de enamoramiento:

Los personajes de la Segunda Celestina se agrupan según un proceso gradatorio que ubica a cada uno desde el materialismo de la vieja hechicera y sus sobrinas, o del criado Pandulfo, pasando por el materialismo más moderado de criados como Sigeril y Poncia para los que sus afanes económicos no entran en conflicto con sus obligaciones de lealtad hacia sus amos, hasta llegar finalmente al idealismo de la pareja protagonista [...] que son Felides y Polandria. (Sales Dasí 2001: 404) 
Se realiza a través de las cartas, serenatas y poemas que Felides le dedica y sin la intervención mágica de la alcahueta. Sara Sánchez Bellido escribe al respecto de la presencia de las cartas en el proceso amoroso:

Sin embargo, en la Segunda Celestina se le otorga un papel de gran relevancia a las misivas que Felides y Pandulfo dirigen a Polandria (además de éstas aparecen una de Sigeril a Poncia y otra de Zambrán a Boruca). Las cartas no sólo son leídas en escena y objeto de discusiones acerca de su retórica, lo que sirve para "caracterizar tanto al remitente como a los auditores», sino que parecen, a simple vista, el origen del enamoramiento de la dama: «si yo no viera la carta de Felides haviendo visto su hermosura, no desseara el coraçón lo que la razón aborrece». (757)

María José Navarra Gala analiza las diferentes cartas de amor presentes en la obra de Silva e indica la parodia que subyace en todas ellas. No obstante, está también claro que la carta de Felides, a pesar de su retorcida retórica, tiene el éxito deseado: el amor de Polandria, lo cual ya había dejado claro Heugas (1973: 286) ${ }^{7}$. Navarro Gala dice del poder persuasivo de la retórica de Felides:

Así pues, lo verdaderamente significativo en la funcionalidad textual de la comedia es la evidencia de que la paródica carta de Felides se instituye como poderoso, eficaz y seguro instrumento de persuasiva seducción a pesar de su procaz contenido y gracias, exclusivamente, al uso de una elocutio preciosa y alambicada. (Navarro Gala 2004: 86)

La retórica preciosista y rebuscada de Felides, sus romances y canciones presentadas en la noche, enamoran a Polandria y ningún obstáculo mercantilista inhibe su relación realmente, por lo cual su relación es en cierta medida el contraejemplo para las demás relaciones que principalmente se organizan según una lógica mercantilista.

\section{Conclusiones}

Se ha visto que la obra se crea, al igual que su modelo, en un mundo de una desenfrenada mercantilización. Feliciano de Silva radicaliza los elementos mercantilistas ya presentes en la Tragicomedia rojana (Sánchez

7.- «La rhétorique de Félides a touché celle a qui elle était destinée et la seule qui pouvait la comprendre» (Heugas 1973: 286). 
1994: 61) ${ }^{8}$ presentando una serie de discursos amorosos que conceptualizan las relaciones entre personas principalmente regidas por el dinero.

La obra pone, pues, de relieve la reificación que se lleva a cabo a partir del mercantilismo. El proceso de «apreciar» el valor de una persona según el tamaño de su hacienda, la valoración del beneficio de una relación por el aprovecho económico que esta puede significar, un distanciamiento entre las personas, son elementos que están en el debate alrededor del término «Verdinglichung» desde Marx y Lukács y ahora en los trabajos de Axel Honneth. El ve un olvido del reconocimiento fundamental del otro en la raíz de la cosificación de las personas:

Insofern entspricht jenem Vergessen vorgängiger Anerkennung, das ich als den Kern aller Vorgänge der Verdinglichung begreifen möchte, auf der anderen Seite tatsächlich auch das Ergebnis einer perzeptiven Verdinglichung der Welt: Die soziale Umwelt erscheint, nahezu wie in der Wahrnehmungswelt des Autisten, als eine Totalität bloß beobachtbarer Objekte, denen jede psychische Regung oder Empfindung fehlt. (Honneth 2015: 68)

José Mondéjar había apuntado sobre la Segunda Celestina que es un «retrato de un tipo de sociedad estamental, cuyo único lazo de relación posible entre los estratos socioeconómicos principales (el bajo fondo y la clase adinerada) es el 'amor' como mercancía de compraventa, servido por chulos, bravucones cobardes, criados sin escrúpulos y alcahuetas» (2000: 221).

La cosificación de la persona es un elemento muy presente en la obra de Feliciano de Silva que llega hasta el discurso amoroso, por lo cual su texto, lejos de significar una vuelta a un supuesto mundo medieval, se inserta en el discurso mercantilista de su época. 


\section{Bibliografía}

Baranda, Consolación (1988), "Introducción», en Feliciano de Silva, Segunda Celestina, ed. Consolación Baranda, Madrid, Cátedra, pp. 25-104.

Casey, James (1999), Early Modern Spain. A social history, London, Routledge.

Esteban Martín, Luis Mariano (1991-1992), «Feliciano de Silva en el ciclo celestinesco", La Corónica, 20-2, pp. 42-49.

Franco, Guiseppe (2015), Da Salamanca a Friburgo: Joseph Höffner e l'economia sociale di mercato, Città del Vaticano, Lateran University Press.

Gómez Rivas, León (1999), «Business Ethics and The History of Economics in Spain 'The School of Salamanca: A Bibliography', Journal of Business Ethics, 22-3, pp. 191-202.

Grice-Hutchinson, Marjorie (1952), The School of Salamanca, readings in Spanish monetary theory 1544-1605, Oxford, Clarendon Press.

- (1992), "Contributions of the School of Salamanca to Monetary Theory», en Economic Effects of the European Expansion, ed. José Casas Pardo, Stuttgart, Franz Steiner, pp. 173-198.

Heugas, Pierre (1973), "La Célestine» et sa descendance directe, Bordeaux, Éditions Bière.

HONNETH, Axel (2015), Verdinglichung, eine anerkennungstheoretische Studie, um Kommentare von Judith Butler, Raymond Geuss und Jonathan Lear erweiterte Ausgabe, Frankfurt am Main, Suhrkamp.

Melé, Domènec (1999), "Early Business Ethics in Spain: The Salamanca School (1526-1614)», Journal of Business Ethics, 22-3, pp. 175-189.

Menéndez Pelayo, Marcelino (1943), Orígenes de la novela, IV, Primeras imitaciones de la "Celestina», ed. Enrique Sánchez Reyes, Santander, CSIC.

MondéjAr, José (2000), "Cultismo y popularismo en la Segunda Celestina (1534)", en El mundo como contienda, estudios sobre la Celestina, ed. Pilar Carrasco, Málaga, Analecta Malacitana, pp. 221-239.

Navarro Gala, María Josefa (2004), «La parodia de la carta de amores en la Segunda Celestina», Celestinesca, 28, pp. 69-99.

- (2004), "Formas de cortesía en la Segunda Celestina» en Pragmática sociocultural: estudios sobre el discurso de cortesía en español, eds. Diana Bravo y Antonio Briz, Barcelona, Ariel, pp. 213-226.

Rodríguez Cascante, Francisco (2001), "La seducción de Celestina y el honor de Melibea en la recepción de Feliciano de Silva», Celestinesca, 25, 1-2, pp. 21-46. 
Sales Dasí, Emilio José (2001), «Feliciano de Silva, aventajado 'continuador' de Amadises y Celestinas» en "La Celestina» V Centenario (14991999) Actas del congreso internacional, Salamanca - Talavera de la Reina, Toledo - La Puebla de Montalbán, 27 de septiembre a 1 de octubre de 1999, ed. Felipe B. Pedraza Jiménez, Rafael González Cañal y Gema Gómez Rubio, Cuenca, Universidad Castilla-La Mancha, pp. 403-414.

Sánchez Bellido, Sara (2010,, "El sistema de relaciones en el ciclo celestinesco: el caso de la Segunda Celestina y la Tragedia Policiana», en Estudios sobre la Edad Media, el Renacimiento y la temprana modernidad, eds. Francisco Bautista Pérez, Jimena Gamba Corradine, San Millán de la Cogolla, Semyr-CiLengua, pp. 753-762.

Sirva, Feliciano de (1988), Segunda Celestina, ed. Consolación Baranda, Madrid, Cátedra.

Vian Herrero, Ana (1997), "Transformaciones del pensamiento mágico: el conjuro amatorio en La Celestina y en su linaje literario» en Cinco siglos de "Celestina»: Aportaciones interpretativas, ed. Rafael Beltrán, José Luis Canet, Valencia, Universidad de Valencia, pp. 209-238. 
